Connotas. Revista de crítica y teoría literarias 


\begin{tabular}{|ll|}
\hline PQ6001 & Connotas. Revista de crítica y teoría literarias / \\
Director Fortino Corral Rodríguez.-Hermosillo, Sonora: \\
unIson. Departamento de Letras y Lingüística. \\
C2011. \\
V-: $23 \mathrm{~cm}$. \\
Semianual \\
Año VII, No. $12(2011)$ \\
ISSN: 1870-6630 \\
Incluye bibliografía. \\
1. Literatura española - Historia y crítica-Publicaciones \\
periódicas. 2. Literatura hispanoamericana - Publicaciones \\
periódicas. I. Corral Rodríguez, Fortino, dir.
\end{tabular}

CONNOTAS. REVISTA DE CRÍTICA Y TEORÍA LITERARIAS. Año VII, núm. 12, enero junio 2011, es una publicación semestral editada por la Universidad de Sonora, a través de la División de Humanidades y Bellas Artes, en el Departamento de Letras y Lingüística. Blvd. Luis Encinas y Blvd. Rosales s/n, Col. Centro, C.P. 83000, Hermosillo Sonora; Tel. (662) 2592 136, (662) 2592 157, <www.uson.mx>, <http://www.connotas.uson.mx, connotas@capomo.uson.mx>. Editor responsable: Rosario Fortino Corral Rodríguez. Reservas de Derechos al Uso Exclusivo núm. 04-2006-020714184900-102. ISSN: 1870 6630; ambos otorgados por el Instituto Nacional del Derecho de Autor. Licitud de Título núm. 13434 y de Contenido núm. 11007, otorgados por la Comisión Calificadora de Publicaciones y Revistas Ilustradas de la Secretaría de Gobernación. Impresa en Impresos RM S.A. de C.V., Privada Miguel Alemán no. 17, col. San Benito, Hermosillo, Sonora, México. Tel. 2 100212, e-mail impresosrm@gmail.com. Este número se terminó de imprimir el 5 de octubre de 2011 con un tiraje de 300 ejemplares. Las opiniones expresadas por los autores no necesariamente reflejan la postura del editor de la publicación.

Se autoriza la reproducción total o parcial de los contenidos de la presente publicación, siempre y cuando se acredite adecuadamente el origen de los mismos.

Este número se publicó con apoyo del Programa Integral de Fortalecimiento Institucional

Datos de contacto para la publicación: División de Humanidades y Bellas Artes, Departamento de Letras y Lingüística; Apartado Postal 793, Col. Centro, C.P. 83000, Hermosillo, Sonora, México. Tels.: (662) 259-21-87, Tel-fax 212-55-29. Correo electrónico: connotas@capomo.uson.mx Página web: http://www.connotas.uson.mx 


\section{Connotas. Revista de crítica y teoría literarias}

Año VII / Núm. 12 / Enero-junio 2011

COMPILAdOR DE ESTE NÚMERO

César Avilés Icedo

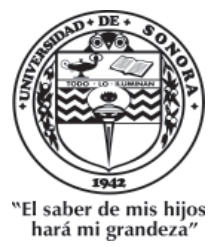

UNIVERSIDAD DE SONORA 


\section{UNIVERSIDAD DE SONORA}

RECTOR

Heriberto Grijalva Monteverde

VicerReCTORA

Arminda Guadalupe García de León Peñúñuri

Secretario General Académico

Enrique Fernando Velázquez Contreras

División de Humanidades y Bellas Artes

María Rita Plancarte Martínez

DePARTAMENTO DE LETRAS Y LINGÜÍSTICA

Martha Martínez Figueroa

COMItÉ EDITORIAL INTERNO

César Avilés Icedo

Rosa María Burrola Encinas

Fortino Corral Rodríguez

Leticia Martínez Figueroa

Jesús Abad Navarro Gálvez

Gabriel Osuna Osuna

María Rita Plancarte Martínez

DiRECTOR

Fortino Corral Rodríguez

Giuseppe Bellini

Universidad de Milán

Luis Beltrán Almería

Universidad de Zaragoza

Helena Beristáin

Universidad Nacional Autónoma de México

Raúl Bueno-Chávez

Dartmouth College

Evodio Escalante

Universidad Autónoma Metropolitana

Beatriz González-Stephan

Rice University

Aníbal González Pérez

Yale University

Aurelio González Pérez

El Colegio de México

Yvette Jiménez de Báez

El Colegio de México

Nelson Osorio Tejeda

Universidad de Santiago de Chile

\section{CONSEJO INTERNACIONAL}

Carlos Pacheco

Universidad Simón Bolivar

Rafael Olea Franco

El Colegio de México

Joan Oleza Simó

Universidad de Valencia

Julio Ortega

Brown University

Luz Aurora Pimentel

Universidad Nacional Autónoma de México

Susana Reisz

The City University of New York

José Carlos Rovira

Universidad de Alicante

Charles Tatum

The University of Arizona

Jorge Urrutia

Universidad Carlos III de Madrid

Emil Volek

Arizona State University 


\section{Índice}

\section{Artículos}

La ciudad fronteriza de Luis Humberto Crosthwaite en Estrella de la calle sexta e Instrucciones para cruzar la frontera

Martín Torres SAUChetT . . . . . . . . . . . . . 9

Artífices y simuladores: el influjo de los medios masivos y la cultura popular en la literatura latinoamericana del siglo XX Amalia Franco Castaño . . . . . . . . . . . . . . . . . 27

“Teoría del túnel”: El pre-texto de Rayuela Margarita Díaz de León Ibarra . . . . . . . . . . . . . . 45

Metaficción hispanoamericana y crisis de la representación literaria del sujeto

Jesús Eduardo Oliva Abarca . . . . . . . . . . . . 61

Los refranes y los poemínimos: análisis de una relación intertextual

IsAbelle Pouzet . . . . . . . . . . . . . . . . . . . . . . . . 79

\section{Notas}

La ciudad como categoría estética e ideológica en Cartas de relación de Hernán Cortés y Grandeza mexicana de Bernardo de Balbuena Jesús Abad Navarro Gálvez . . . . . . . . . . . . . . . . . 99 
Hacia una hermenéutica estridentista: de la crítica romántica a la crítica de vanguardia

Alberto Rodríguez González . . . . . . . . . . . . . . . . 111

Casas de encantamiento y El espía del aire, de Ignacio Solares: la reflexión de la escritura

Alejandra Sánchez Aguilar . . . . . . . . . . . . . . . . . . 123

\section{Reseñas}

Gilberto Giménez. Estudios sobre la cultura y las identidades sociales. México: Conaculta/ITESO, 2007

Ana Lourdes Álvarez Romero . . . . . . . . . . . . . . . . . . . 135

Angélica Tornero. El mal en la narrativa de Inés Arredondo. México: Casa Juan Pablos/Universidad Autónoma del Estado de Morelos, 2008

Griselda Córdova Romero . . . . . . . . . . . . . . . . . . . . . . . 141

Guadalupe Fernández Ariza, coord. Literatura hispanoamericana del siglo XX. Historia y maravilla. España: Universidad de Málaga, 2006

Mayra Alejandra Borbón Espinoza . . . . . . . . . . . . . . 147

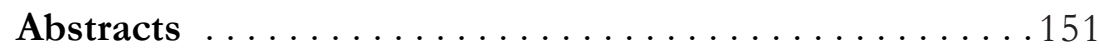

Résumés ... . . . . . . . . . . . . . . . . . . . . 157

Normas editoriales ..................... 163 
CONNOTAS. REVISTA DE CRíTICA Y TEORÍA LITERARIAS/AÑo VII, NúM. 12/2011

\title{
Artífices y simuladores: el influjo de los medios masivos y la cultura popular en la literatura latinoamericana del siglo XX
}

\author{
Amalia Franco Castaño*
}

Resumen:

Con el advenimiento del desarrollo tecnológico y con la pugna entre cultura popular y cultura de los medios masivos, ocurre una transformación que influye en la construcción de imágenes representativas de la memoria, la historia y el conjunto de anhelos de los sujetos. Dicha transformación incide ostensiblemente en la construcción de personajes y anécdotas identificables en la literatura latinoamericana del siglo Xx, en la que se plantea una lectura del sujeto latinoamericano que no niega la influencia de los medios y que incluso los plantea como mecanismos decisivos para la exploración de su conciencia. Se trata entonces de observar, a la luz de los conceptos de popular y masivo, la incidencia de este fenómeno en la novela latinoamericana del siglo pasado.

Palabras clave:

Mass media, literatura popular, Puig, sujeto, literatura culta.

Cuando Arsenio Cué, una de las voces de Tres tristes tigres, examina sin mayores pretensiones "metafísicas" la exhibición como una condición humana, afirma: "no será el hombre una criatura que se exhibe ante el cosmos en este enorme convertible que es el mundo"

\footnotetext{
* Universidad Minuto de Dios.
} 
(160). Su auto, la emulación de un papel hollywoodense y la imagen cinematográfica de Andy Hardy le permiten justificar para sí mismo la postura ilegítima con la que alguna vez protagonizó sus recuerdos y la manera en que son reajustados según su propia selección y combinación: "He visto demasiadas películas de la Metro para no haber cometido el error de no querer ser un cubano típico en ese momento [...]" (Cabrera160).

Poco más tarde, y en otro paisaje literario, Raba -sirvienta de los Aschero-, en Boquitas pintadas, se sirve del argumento de una película argentina como planteamiento hipotético sobre importantes decisiones futuras:

Raba pensó en la película argentina que había visto el viernes anterior, con su actriz-cantante favorita, la historia de una sirvienta de pensión que se enamora de un pensionista estudiante de abogacía. ¿Cómo había logrado que él se enamorase de ella? la muchacha había sufrido mucho para conseguirlo y Raba se dio cuenta de algo muy importante: la muchacha nunca se había puesto a enamorarlo, el había empezado a quererla porque la veía buena y sacrificada [...] Raba decidió que si alguien de otra clase social, superior, un día le proponía matrimonio ella no iba a ser tonta y rechazarlo, pero tampoco sería ella quien lo provocase... (Puig 76)

Tanto en los ejemplos de Cabrera Infante como en los de Manuel Puig, la introspección de los personajes como mecanismo de la exploración de la conciencia se sirve de materiales que en otro espacio y en otro tiempo hubiesen sido tachados de frívolos e intrascendentes. En Tres tristes tigres y Boquitas pintadas, estos materiales son objeto de pasiones desde donde los personajes encuentran una proyección de sí mismos; los medios masivos encarnan una serie de representaciones sociales, de relaciones del individuo con su historia y con su memoria, que transforman y restituyen la idea de "sujeto."

La literatura latinoamericana del siglo XX, que no ha sido ajena a este influjo, integra desde una condición crítica y estética los va- 
lores de su entorno, donde los "productos culturales" masivos (como guiones de cine, la radio, la televisión, la informática y programas de computación, etc.) les sirven a los personajes para consolidar su discurso. Así, los medios se convierten en el artificio desde el cual es posible reinventarse y orientar la mirada.

Para reificar estas inclusiones de lo popular y lo masivo en lo literario como un procedimiento estético y apuesta del autor, las reflexiones se han inclinado a precisar y diferenciar conceptos como 'cultura popular' y 'cultura de medios masivos;' incluso podríamos decir que la discusión inicia precisamente en reconocer en qué momento lo popular dejó de ser lo popular y comenzó a llamarse 'cultura popular,' o en qué momento los medios masivos dejaron de ser una amenaza y comenzaron a contemplarse como claves para entender problemáticas y manifestaciones socioculturales.

Fuera de la ficción, la categoría de culto en oposición a popular sugería un cúmulo de prácticas que paulatinamente se constituyeron en hegemónicas sobre la base del consenso y el sistema de clases. Se establece, entonces, una relación de poder y de resistencia, en la cual a las manifestaciones populares les compete la práctica del disenso frente a lo canónico, lo establecido y lo normativo. Gramsci define lo popular precisamente como una clase subalterna que se repite en cada una de las formas sociales hasta ahora dadas. Lo popular, como subalterno a esa hegemonía propiciada por la alta cultura, no comparte la constitución homogénea de ésta, sino que se caracteriza por una concepción de mundo menos sistemática y cerrada, más dispuesta a la posibilidad de reinventarse y de apropiarse constantemente de símbolos y arquetipos.

El panorama de oposiciones entre alta y baja cultura sobrevivió durante el siglo XIX como una lucha perenne entre clases. Esta situación se traslada al terreno de la literatura -específicamente a la novela-, en donde no sólo se evidencia la contraposición de discursos sino que, además, aparecen los "modelos" de clase alta y baja, que en definitiva constituyen la representación de lo popular frente a la élite. A este respecto, Carlos Monsiváis escribe: "La novela del siglo XIX es clasista y así debe serlo en el universo de categorías inescapables, donde la más rara de las costumbres es la movilidad 
social. Pero, también deja de ser clasista al describir con calidez atmósferas y modos de vida, y al trazar positivamente personajes "de las clases bajas"” (15).

El comentario de Monsiváis se dirige a mostrar cómo en la novela latinoamericana lo popular, en oposición a lo oficial o lo culto, implicaba la constitución de "ubicaciones simbólicas" para cada una de las clases. Ubicaciones que fueron cediendo cuando en las sociedades se replantearon la posición de dichas esferas. Monsiváis ilustra, además, cómo las referencias a lo popular dentro del discurso literario estuvieron marcadas por la apreciación y el punto de vista de la élite sobre el pueblo, creando un arquetipo basado en la figura del pobre:

Metáforas del vicio y la resignación, los pobres ornamentan las novelas del naturalismo como ángeles caídos: no intuyeron la decencia y la degradación que los consumió, o -lo más frecuente- nacieron viles y refrendaron el estigma con su abandono. Según el naturalismo, lo popular es sordidez, falta de control, olores insalvables, inmoralidad impuesta por los rasgos faciales y el color de la piel, animalización que es credo de la sobrevivencia. (16)

Así se perfilan una serie de personajes "condenados" a la marginalidad y a la pobreza; expresiones de lo popular que, como lo muestra el estudio de Monsiváis, reproducen una suerte de abstracciones que reducen y estereotipan la imagen del pueblo a través de lo inhóspito y lo desesperanzado. Raba, el personaje antes mencionado, idealiza a los personajes cinematográficos subrayando precisamente su condición marginal y excluida.

Si bien lo popular y sus representaciones han mantenido durante la historia la imagen de unión y de familia (nacionalismo, movimientos libertarios, etc.), los temas literarios que incluyen lo popular reflejan también la imagen de decadencia y aislamiento donde el porvenir, como posibilidad para evolucionar y transgredir el destino al que han sido lanzados, es irrealizable. Ejemplo de ello son las novelas de corte realista en Latinoamérica, que recogen la costum- 
bre del pueblo que se reconoce en el campo, desde donde su experiencia aparentemente es más auténtica.

Para el caso de Colombia, por ejemplo, lo popular estuvo centrado en la exaltación de la naturaleza costumbrista, que a finales del siglo XIX y principios del XX esbozaba una mirada del campo totalmente idealizada, pero al mismo tiempo ajena y menor. En Bogotá, las revistas y suplementos literarios de la época corresponden a ciertos ideales que obedecen al proyecto de Núñez y Caro por reforzar los valores de la "patria" acentuando para ello la constitución de unos principios estéticos de corte neoclásico. Antes de El Tradicionalista ya había aparecido en Bogotá un proyecto de periodismo literario bajo el nombre de El Mosaico (1858), que suponía un programa exclusivamente literario, a diferencia de publicaciones anteriores dirigidas al "bello sexo" y a la conservación de ideas religiosas. Desde esta perspectiva la inclusión de temas populares no se devela como una manifestación cultural en oposición a la cultura oficial, sino que se convierte en instrumento ideológico y político de la ciudad letrada.

Desde otras manifestaciones estéticas, el reflejo de las costumbres, la consideración de la pobreza y sus consecuencias en las acciones de los hombres se constituyeron, dentro del relato literario, en punto de partida para referirse a lo popular. Además de esto, se incluían rasgos como el habla popular, la jerga, los ademanes y demás signos que determinan y singularizan al pueblo. La literatura se ha referido entonces a lo popular desde dos estigmas: el primero como exaltación del paisaje ideal del campo y el campesino, y el segundo como la naturaleza adversa y desventajosa que rodea a la pobreza y por ende al pueblo; condición que se extiende incluso hacia comienzos del siglo XX: "Todavía a mediados del siglo XX, las élites califican de 'primitivo' a la mayoría de los habitantes de América Latina, y se complacen en la teoría del pueblo ignaro y abúlico, del 'vulgo irredimible' otorga la simpleza de alma" (Monsiváis 24).

Cuando la novela se traslada a las urbes, o ante la propuesta de otra mirada sobre la naturaleza y el campesino, lo popular no alcanza ya a percibirse como una estrategia social unida y homogénea; más bien, su composición se ve asaltada por respuestas y sentires 
disímiles, producto de las continuas adaptaciones a las que son expuestas. De manera paulatina, la visión de lo popular dentro de la literatura comienza a adquirir otras dimensiones e interpretaciones.

Las representaciones de lo popular se incorporan a partir de contenidos distintivos de cada época. Así, el contenido del cine y las revistas, en la década de los sesenta, se transforma en la actualidad a contenidos representados en la tecnología y en otros medios masivos, que, aunque distintos, conservan la intención de ofrecer lecturas del sujeto social y de su medio. La manera en que estos contenidos han sido incluidos en la literatura va desde la nominación repentina de los mismos hasta la propia constitución de la obra a partir del lenguaje mediático y popular.

La relación de dominación y resistencia que se daba entre la "alta cultura" y la cultura popular se ve asaltada por la intersección de otro fenómeno resultado del capitalismo: "Más tarde se piensan y se fracturan lo límites presentes entre ambos elementos (la alta y baja cultura). Los límites se vuelven difusos; hay que concentrarse entonces, en las conexiones. Y finalmente, incluso, se rompe el binarismo inicial al incluir una terceridad: la cultura de masas" (Blanco 19). Desde la literatura, lo popular adopta poco a poco otra imagen que se reconoce ya no desde la condición marginada y excluida, sino desde lo cotidiano, de los saberes comunes y de las prácticas ordinarias que vinculan a un gran número de sujetos cuyas vidas se ven asaltadas por el cúmulo de imágenes de la publicidad y de los medios, de los cuales reconocen elementos para representarse a sí mismos.

La cultura no es vista, entonces, como un estructura significante, sino como intercambio y relación, lo que implica que se reconozcan los contenidos expresados en situaciones específicas de diálogo; por lo cual, la lectura de lo latinoamericano pasa por la construcción y materialización de discursos a partir de los referentes que proceden de diversos lugares. De la misma manera, el cruce de producciones discursivas que retoman la dinámica y los objetos de los medios masivos afecta sustancialmente la condición de identidades como sistemas fijados a una experiencia y a una tradición, haciéndolas más inestables y más dependientes del compromiso 
estipulado por el sujeto y su deseo de compartir o no compartir los signos de su cultura.

Pronto lo representado y lo construido por los personajes pone en tela de juicio la validez del referente. Los países, las ciudades, la historia y la memoria resultan maleables, y los objetos de los que se sirven se ubican en los productos de la cultura popular y los medios masivos. Es un punto de partida desde donde pueden manipular la dimensión del tiempo y el espacio: "Es la ruptura operada en el espacio lo que permite la construcción del mundo, pues es dicha ruptura la que descubre el 'punto fijo' el eje central de toda orientación futura" (Eliade 28).

Massiello alude (aunque no en la misma dirección que se le da a este trabajo) a la escritura memorística como una característica de las novelas bestseller. Desde la perspectiva de esta autora, entendemos cómo la posibilidad de hacer "coincidir el fluir de la historia con las propias elecciones subjetivas" (69) se convierte en un mecanismo atractivo, en el cual aparentemente se ofrece una posibilidad de intervenir -e incluso modificar- la historia desde la individualidad. Desde allí, podemos reconocer que los personajes literarios en contacto con la cultura se mueven desde el dinamismo que permiten los medios.

La cultura no funciona entonces como una suma perenne de experiencias que distinguen o caracterizan a una comunidad. Las expresiones de novelas como Ella cantaba boleros y La traición de Rita Hayworth llevan a entender el fenómeno de la cultura desde su naturaleza "cronotópica," que tiende a reconocer los mecanismos y mediaciones entre prácticas culturales como inseparables de las mentalidades y las experiencias que surgen con cada época, en la que incluso la dimensión ficcional de un film reemplaza o se convierte en intermediaria de la realidad. Los procedimientos expuestos en estas novelas permiten replantear la concepción recalcitrante de cultura, que la define desde relaciones invariables y clasificables, y revalúan las oposiciones entre diversas expresiones de la cultura, como el caso de la cultura popular en oposición a la cultura oficial.

Desde esta ambivalencia y cruces entre ambas culturas (la cultura popular y mediática) se construye una serie de narrativas que 
dan lugar a un buen número de novelas a finales del siglo XX, cuando los medios masivos y sus lenguajes cobran gran protagonismo. Para el caso del escritor Alberto Fuguet, la globalización y el neoliberalismo, así como el acceso a las nuevas tecnologías, inciden ostensiblemente en la constitución de sus personajes y sus marcos narrativos: jóvenes chilenos en constante conflicto con su historia y con la sociedad que los rodea; situaciones cotidianas que enmarcan una clara relación de dependencia con los medios y con la cultura de masas; y personajes abyectos como resultado de inadecuación a su espacio y circunstancias históricas. Por ejemplo, en la novela Por favor, rebobinar, el personaje Lucas García configura su vida a través del video y el cine (trabaja en un videoclub). Para él, los sucesos de la vida se acumulan como escenas para un proyecto cinematográfico. "Pensar en películas" implica la constitución de una serie de íconos a través de los cuales valora la vida real; el cine y los medios audiovisuales, como alegoría de la vida de Lucas, se insertan en el discurso del personaje hasta el punto de conformar un lenguaje y una forma única de relacionarse con los demás. Se produce, entonces, una relación que opera bajo la lógica de "objeto-signo," en la cual los objetos encarnan valores de distinción de clase, de conjunto de aspiraciones y delimitación de la diferencia. Lucas encuentra en esos objetos el signo que le permite inclinarse ante ciertas personas o rechazarlas; los objetos y los sentimientos que despierten en la gente son síntomas de su personalidad.

En Vida feliz, de un joven llamado Esteban, del colombiano Santiago Gamboa, se explora una suerte de recursos que alimentan la narración autobiográfica; desde allí se ponen de manifiesto consideraciones frente al fenómeno del artista, en las cuales se subrayan las limitaciones sociales y económicas que subordinan o demeritan la condición del escritor frente a otras profesiones más lucrativas en las sociedades actuales: "Me gano la vida escribiendo. Sobre todo informativos de radio y prensa, pero también novelas, pues así me de vergüenza tengo aspiraciones literarias" (11). La literatura se asume, entonces, desde su lugar en la "industria cultural," a partir de las relaciones que desprende, desde las actitudes sociales y comerciales que un escritor debe estar dispuesto a asumir y desde 
el "compromiso" cultural que se confirma en estereotipos y frases de cajón.

En Sobredosis, Fuguet presenta cinco relatos cuyos protagonistas emiten una versión de los pequeños mundos a los que han llegado a convertirse sus vidas en la inmensidad de un Chile progresista. La alusión a los medios masivos, a la moda y al rock del momento comienza a replantear la referencia norteamericana que se incrusta sin ninguna dolencia en sus diálogos y en sus representaciones simbólicas. Las drogas, la violencia, el cine y el ruido no son en estos cuentos el único estigma de una generación; estos elementos y los intercambios con otras culturas arrojan el sentimiento de una época que reorganiza y reorienta el espacio de un sujeto latinoamericano durante la década de los ochenta y de los noventa.

Las palabras en inglés y las actividades comerciales de la vida social de Miami o New York aplazan para los jóvenes la posibilidad de lamentarse de su historia. La mayoría de las anécdotas que componen el libro se ven atravesadas por una necesidad: huir. Huir de su pasado, huir de su realidad inminente, arrojarse a las posibilidades de otras lenguas o al mensaje codificado de una canción de Guns and Roses; posibilidades que tienen serias consecuencias para la concepción de la realidad que experimentan los personajes. En el cuento que cierra el libro, "No hay nadie allá afuera," la conclusión frente a la invasión de los medios y la cultura norteamericana terminan con la siguiente sentencia: "Estoy solo, en América, recorriendo un Nueva York a punto de ser nevado, dándome cuenta de que uno puede escapar de todo menos de uno mismo" (123). En la obra posterior a la publicación de estos cuentos, la referencia a la cultura norteamericana y a la cultura de los medios masivos se ve justificada en cada una de las historias por la necesidad de emplear este tipo de representaciones como mecanismo para dar cuenta de lo que dentro de los estudios culturales podría denominarse "configuración simbólica” de una cultura. La resolución de los protagonistas en estas historias no los lleva directamente a la felicidad; tampoco es una expresión abierta de libertad, ya que dichas reconstrucciones se encuentran afectadas por los diversos impactos que se generan a partir de la recepción de la cultura de masas: "El con- 
sumo en el mundo contemporáneo, es decir, como parte del proceso civilizatorio capitalista, es por lo general una forma de trabajo y obligación. De todos modos, donde hay consumo hay placer, y donde hay placer hay agencia. La libertad, por otro lado, es una mercancía bastante más escurridiza e inalcanzable" (Appadurai, "La aldea").

El paisaje mediático, ${ }^{1}$ caracterizado por la distribución de tecnologías para la producción y distribución de la información, provee "imágenes, narraciones y paisajes étnicos" para consolidar esos mundos imaginados. La capacidad para mantener la distinción entre realidad y ficción se desprende de la perspectiva y del lugar del mundo del que evalúa. Los personajes de estas ficciones recurren a la constitución de mundos imaginarios que les permiten consolidar la fantasía de mudarse a otros lugares, de mantener otros diálogos y construir por fin el sujeto, la ciudad o el país que anhelan. Estos paisajes como "constructos" son el resultado de condiciones históricas, lingüísticas y políticas de los actores involucrados;" son, en última instancia, un material recolectado de las influencias cercanas, y por ende se constituyen a partir de distintos contenidos que, como bloques de lego, dependen de la capacidad creativa e imaginativa de sus creadores. Se trata, entonces, de reconocer la imaginación como "un hecho social colectivo" que es a la vez plural y diverso.

Este paisaje mediático se convierte en la materia que permite reconstruir a partir de la imaginación la idea de una vida propia y de las vidas de otros lugares. A través de "guiones de vidas imagina-

${ }^{1}$ Appadurai señala: “" "paisaje' hace alusión a la forma irregular y fluida de estas cinco dimensiones (a) paisaje étnico, b) paisaje mediático, c) paisaje tecnológico, d) paisaje financiero y e) paisaje ideológico], formas que caracterizan tanto al capital internacional como a los estilos internacionales de vestimenta. Todos estos términos, que tienen en común la palabra 'paisaje', también intentan hacer notar que no se trata de relaciones construidas objetivamente, que se mantienen fijas con independencia del ángulo desde donde se las mire [...] De hecho, el locus final de este conjunto de paisajes perspectivos es el propio actor individual, puesto que estos paisajes son eventualmente recorridos por agentes que viven y conforman formaciones mayores, en parte como resultado de su propia interpretación y sentido de lo que estos paisajes tienen para ofrecer." (8-9) 
das," los personajes reorganizan sus vidas, proyectan su deseo de vivir en otros lugares e incluso demarcan las condiciones de lugar y arraigo. Otras veces, como en "Ícaro," el cuento de Sergio Pitol, la referencia a Rashomon no sólo colabora para la descripción de espacios dentro de la narración, sino que es la película la que exhorta al recuerdo e incluso a la posible resolución de la incógnita sobre la muerte de alguien.

La imaginación dentro de este panorama no es exclusiva de sujetos dotados artísticamente; por el contrario, traspasa estas fronteras: ha pasado a formar parte del trabajo mental cotidiano de la gente común y corriente. Es decir, ha penetrado la lógica de la vida cotidiana de la que había sido exitosamente desterrada. "Las personas comunes y corrientes han comenzado a desplegar su imaginación en el ejercicio de sus vidas diarias. Esto se ve en el modo en que mediación y movimiento se contextualizan mutuamente" (Appadurai, "La aldea global"). La imaginación tiene entonces dentro de las sociedades actuales la construcción de un proyecto que incluye la construcción de la imagen del Yo y la constitución de un proyecto social cotidiano; este procedimiento ya nos lo había ofrecido Roberto Arlt a través de Endorssain, un personaje marginal que halla en la imaginación la proyección del sujeto que desearía llegar a ser. Los insumos con los que alimenta su imaginario no proceden directamente de productos masivos, como en el caso de los personajes de Fuguet y Paz Soldán, pero son en última instancia alimentados por un ideal construido y han reificado aspiraciones colectivas. Incluso la suerte trágica del personaje es anunciada por un periódico local; los medios, en este caso, se convierten en ayudantes de la descripción narrativa.

El lugar de lo mediático como presupuesto para explicar la psiquis de un personaje se encuentra fuertemente ligado a una reorganización social afectada por el pensamiento posmoderno. Este periodo -según Jameson- se encuentra atravesado por una inclinación a la cultura de masas, que consiste en entrar en una dinámica en donde los productos de los mass media se convierten en esencia y sustancia de las producciones estéticas, que sin temor se confunden con lo kitsch, lo televisivo y, en general, con lo popular. 
Dos novelas que ilustran esta tendencia son Sueños digitales, del escritor boliviano Edmundo Paz Soldán, y Esperanto, del argentino Rodrigo Fresán. En ambos casos, los discursos y objetos de los mass media inciden en la constitución de los perfiles psicológicos y axiológicos de los personajes; en ambos, la lectura del espacio, de la historia y de su país se ve claramente afectada por la disposición de esquemas mentales que suponen las sociedades posmodernas inmersas en prácticas determinadas por la exposición de los medios.

En Esperanto, el recurso cinematográfico sirve para establecer el pacto narrativo. La lucidez de la memoria, que en ocasiones contiene recuerdos dudosos y poco certeros, se reordena gracias a este procedimiento literario propuesto por Fresán. La lógica de los medios, como el cine o la televisión, sirve en esta novela para encarar la anécdota sin perderse en la vacuidad del que recuerda sin pruebas. Sebastián, el joven diseñador gráfico protagonista de Sueños digitales, experimenta a través de la novela diversas sensaciones que confunden su experiencia inmediata con las posibilidades de la realidad virtual. El lenguaje, salpicado excesivamente de referencias a la cultura de masas y a la tecnología, se confunde con personajes de la farándula y la política como expresiones "in-auténticas" de su propia vida.

Tanto en Esperanto como en Sueños digitales, se plantea una relación esencial de los personajes con su memoria y su pasado histórico. En los dos casos la intervención de los medios masivos y la cultura popular "afecta" la percepción del recuerdo y la solidez del presente. Por su parte, Rodrigo Fresán nos ofrece una lectura menos afirmativa de la intervención de la cultura masiva en las relaciones humanas. El personaje de Esperanto se encuentra perplejo ante una realidad que desconoce y en la que sólo caben sus anhelos por el pasado; una realidad en la que sobresale la vacuidad de los medios masivos que lo fuerza a resistirse a entrar en una dinámica donde sólo tiene vigencia lo inmediato, lo fútil y lo efímero. Reconstruir su identidad y volver sobre sus pasos se convierte en una empresa difícil y compleja, en tanto que no hay garantía de que sus recuerdos no se vean afectados por la idealización y la falsa percepción de los sucesos. Tal situación también se reconoce en las pági- 
nas de Sueños digitales, en la cual no hay garantía de que la memoria o los recuerdos hayan sido modificados a la manera en que las fotografías se alteran gracias a photoshop.

Paz Soldán introduce con más naturalidad los contenidos de la cultura de masas: las constantes referencias a cadenas de almacenes, películas y bandas de rock se incrustan dentro del discurso de los protagonistas volviéndolos elementales para hablar de cualquier temática. La historia, que involucra temas políticos, de corrupción y gobiernos dictatoriales, pasa por la banda del scanner desde donde se alteran, retocan y rectifican actos acusatorios y censurables. En las novelas se evidencia la recuperación estética del pasado, el cual pasa por el tamiz de los medios, algo que ya habíamos advertido en la literatura de Cabrera Infante y Puig, en la que la expresión del arte cinematográfico se resemantiza como equivalente al recuerdo perdido.

Por otro lado, la expresión de las nacionalidades, esto es, las marcas que definen a un escritor como latinoamericano, se halla, según algunos críticos y escritores, ${ }^{2}$ tamizadas por el velo de lo global y la referencia a lo mediático. No obstante, este aparente desapego repercute en la reconstitución de la identidad literaria latinoamericana a partir de su "nueva" expresión literaria.

Si bien escritores como Sergio Gómez, Rodrigo Fresán, Edmundo Paz Soldán y Alberto Fuguet heredan procedimientos y formas experimentales de escritores de la década de los sesenta, como el grupo mexicano La Onda, Manuel Puig o Roberto Arlt, su propuesta frente a la relación de la literatura con los medios masivos implica un autorrepresentación desde y a través de lo mediático. Proponer lo mediático como único punto de referencia cultural constituye quizás la diferencia más evidente con los escritores precursores en esta línea. Vale la pena subrayar que la utilización de recursos propios de la estética y del lenguaje popular no han tenido para estas obras ni para estos autores las mismas intenciones estéticas o co-

${ }^{2}$ Javier Campos alude a la dificultad para ver en "la literatura de los mcondistas la diversidad de nuestro actual mundo latinoamericano.” (55) 
merciales. Se trata de relaciones determinadas por las realidades históricas latinoamericanas que, como los señala Nelson Osorio, obedece también a transformaciones y crisis en la concepción de mundo. Asimismo, el surgimiento de procedimientos y estéticas que se definen a partir de una renuncia a la tradición sirven para reconocer diferencias en las aspiraciones estéticas de los distintos autores.

Lo orígenes, atribuidos tanto al prólogo-manifiesto de McOndo como al grupo Crack en México, señalan un momento en la cual se redefine, amplia y renueva el concepto de "narrativa latinoamericana." Si en un principio estos dos manifiestos ponían en evidencia la necesidad de reinventarse, de oxigenar las definiciones de lo latinoamericano a partir del distanciamiento de las figuras canónicas de los padres literarios, poco a poco la crítica comenzó a exigir argumentos cada vez más gruesos (de nuevo la solidez que aparentemente ofrece la consolidación de una estética, con nombres, estilos y tendencias homogéneas) que los reafirmara, que no estableciera fisuras entre ellos y que evidenciara la correspondencia entre los manifiestos y las obras. Tales exigencias, desde luego, resultan imposibles de "comprobar" en la medida en que en estos grupos prevalecen la heterogeneidad y la diversidad de estilos, haciendo que la línea que los caracteriza no sea otra que la necesidad de un sembrar colectivo y de afianzarlo a través del desarrollo de proyectos individuales y diferentes.

Para la actualidad, muchos de los escritores y críticos han renunciado a seguir avivando estos proyectos, ya sea porque varios de los escritores, como Fuguet, se rehúsan a seguir respondiendo preguntas al respecto o a continuar dilatando la idea de su pertinencia y evidentes discordancias. La razón no puede ser otra que la lucha contra un estigma que divide y sectoriza la literatura por la edad de sus gestores o el currículo de los mismos: "es duro pero vivimos tiempos en que el escritor va por delante de lo que escribe; así que más le vale ser interesante, divertido, original, recordable, fotogénico, anecdótico. Me refiero aquí, claro, a la percepción extranjera de lo que debe ser un joven escritor latinoamericano..." (Fresán 53). No obstante, permanece la materialización de esas in- 
tenciones; las novelas de Gamboa, Fresán, Palou, Iwasaki, etc., no escatiman en la recuperación de los nuevos discursos mediados por la tecnología y la información; en cada una de ellas prevalece la intención por lograr perfiles que respondan a necesidades y planteamientos estéticos; en cada uno de ellos reposa la singularidad y la formas únicas de ser y dejar de ser del latinoamericano, apelando a las inconmensurables posibilidades de la ficción. Los personajes son entonces el testimonio de un mundo en el que las cuestiones de parentesco o cualquier otro signo de "reproducción cultural" se hacen cada vez más volátiles, obligándolos a elaborar continuas justificaciones sobre sus acciones y la distancia generacional que esto representa.

Teniendo en cuenta lo anterior, la inclusión de la cultura popular y medios masivos dentro de la literatura implica una reflexión que debe detenerse sobre las diferentes acepciones, arquetipos y símbolos con los que se ha constituido la imagen del pueblo y los medios. De desdeñables, alienados y reprimidos, la imagen de los productos culturales que provienen de las masas y los individuos que las componen adopta situaciones relevantes en las cuales la condición de subalternos se oculta y desaparece por acción de su situación protagónica dentro de la historia. A través de los personajes de estas historias, es posible ilustrar cómo se constituye una versión de la identidad y de la cultura, a partir de los efectos de la hibridación y de la multiplicidad. Una multiplicidad que tiene su origen en la ráfaga de imágenes y en la continuidad de redes que se interceptan en el mundo habitado por los personajes, que desconocen fronteras geográficas e idiomáticas.

La identificación con los mitos derivados de los medios masivos y la constitución de una individualidad afectada por la dinámica exigida por estos últimos señalan como condición, en la vida de estos personajes, la confrontación con los estímulos del mundo virtual y de la cultura de masas para reconocerse y darse un espacio en la sociedad. Miradas tan extremas, como la de Lucas, postulan el video y el mundo virtual como salidas posibles y como representaciones (ir)reales de su historia y de los otros. Asimismo, la noción de individuo, de libertad y de identidad se ve afectada por el impac- 
to de los medios masivos y por las dinámicas de contacto que establecen con los receptores, provocando un tipo de individuo que se redefine y reconstituye constantemente de acuerdo con los movimientos y formas de contacto que los sistemas de información proponen. Igualmente, los objetos y los símbolos de la cultura se legitiman de acuerdo con el valor de su posicionamiento en una escala social, en conformidad con cánones y presupuestos de la moda y la cultura de masas.

Sobre esta dinámica de los sistemas culturales globales que parecen afectar la elaboración del sentido de la identidad, es posible afirmar que en la literatura latinoamericana del siglo XX se manifiesta el consolidado de sujetos que imaginan y reconstruyen el sentido de sus vidas a partir de la relación que establecen con los medios. Cada uno de ellos ofrece un aporte para la construcción de un relato en el que se manifiestan "paisajes" como representación del tipo de relaciones culturales que traspasan lo nacional. La exposición aquí presentada va mucho más allá de defender el valor estético de estas obras o su incorporación al canon. Cada una de ellas ha logrado posicionarse en el campo literario respondiendo u oponiéndose a las condiciones estilísticas y expectativas del lector. Cada una de ellas propone en la conciencia de sus actores las posibilidades de reencarnar furtivamente en sujetos idealizados, en reparar su propia historia y ofrecer la voz de la experiencia humana que cede o se resiste a los pormenores de cada época.

\section{Bibliografía}

Appadurai, Arjun. La modernidad desbordada. Montevideo: Tricle FCE, 2001.

. "La aldea global", http:/ / firgoa.usc.es/drupal/node/17381

Arlt, Roberto. Los siete locos. Madrid, España: Cátedra, 2003.

Cabrera Infante, Guillermo. Ella cantaba boleros. Madrid: Alfaguara.1996

. Tres tristes tigres. Barcelona: Planeta, 2005. 
Campos, Javier. "Literatura y globalización: la narrativa chilena en los tiempos del neoliberalismo maravilloso." Literatura chilena hoy. La difícil transición. Eds. Karl Kohut y José Morales. Madrid: Frankfurt/Main, 1999. 255-262.

Eliade, Mircea. Lo sagrado y lo profano. Tr. Luis Gil. Madrid: Ediciones Guadarrama, 1967.

Fuguet, Alberto: Por favor, rebobinar. Santiago de Chile: Alfaguara, 2000. [1999]

Fuguet, Alberto y Sergio Gómez. McOndo. Madrid: Mondadori.1996. Fresán, Rodrigo. Esperanto. Barcelona: Tusquets, 1997.

- Sobredosis. Santiago de Chile: Alfaguara, 1995.

Gamboa, Santiago. Vida feliz de un joven Ilamado Esteban. Barcelona: Ediciones B/Grupo Zeta Z, 2000.

Gramsci, Antonio. Literatura y cultura popular. Tomo I. Buenos Aires: Cuadernos de Cultura Revolucionaria, 1986. [1974]

Jameson, Frederic. Teoría de la posmodernidad. Tr. Celia Montolio Nicholson y Ramón del Castillo. Madrid: Trotta, 1996. [1991]

Masiello, Francine. "La insoportable levedad de la historia: los relatos best sellers de nuestro tiempo." Cuadernos de literatura 8.15 (2002): 88-101.

Paz Soldán, Edmundo. Sueños digitales. Madrid: Alfaguara, 2001.

Pitol, Sergio. Todos los cuentos. México: Alfaguara, 1998.

Puig, Manuel. Boquitas pintadas. Buenos Aires: Sudamericana, 1999. [1969]

—. La traición de Rita Hayworth. La Habana: Casa de las Américas, 1983. 